\title{
SUPORTE NO TRABALHO: A PERCEPÇÃO DE DOCENTES DO ENSINO TÉCNICO
}

http://dx.doi.org/10.5902/2176217110879

\author{
Marinês Verônica Ferreira \\ Universidade Federal de Santa Maria, Brasil.
}

Stefania Tonin

Universidade Federal de Santa Maria, Brasil.

Taís Corrêa Almeida

Universidade Federal de Santa Maria, Brasil.

\section{Vívian Flores Costa}

Universidade Federal de Santa Maria, Brasil.

\author{
Leila Maria Araújo Santos \\ Universidade Federal de Santa Maria, Brasil.
}

\begin{abstract}
Resumo
O estudo foi desenvolvido com o intuito de responder o seguinte problema de pesquisa: quais são as percepções de suporte no trabalho dos docentes inseridos em uma instituição de ensino técnico? Para tanto, realizou-se um estudo de caso descritivo e de caráter quantitativo. A unidade de análise da pesquisa é composta por 17 docentes de um colégio técnico da cidade de Santa Maria, RS. Para coleta dos dados utilizou-se a escala de percepção de suporte social no trabalho (EPSST) e a escala de percepção de suporte organizacional (EPSO). Com relação ao suporte social no trabalho, observou-se que há uma maior percepção do suporte social informacional e do suporte social instrumental. Considerando o suporte organizacional, os docentes apresentam uma percepção elevada da instituição.

Palavras-chave: suporte social no trabalho, suporte organizacional, ensino técnico.
\end{abstract}




\title{
SUPPORT AT WORK: THE PERCEPTION OF TEACHERS \\ OF TECHNICAL EDUCATION
}

\begin{abstract}
The study was developed in order to answer the following research question: what are the perceptions support the work of teachers placed in an institution of technical education? Therefore, we performed a descriptive case study and quantitative character. The unit of analysis of the survey consists of 17 teaching a technical colégico city of Santa Maria - RS. For data collection we used the scale of perceived social support at Work (EPSST) and the scale of perceived organizational support (EPSO). With respect to social support at work, it was observed that there is a greater perception of informational social support and social support instrumental. Considering the organizational support, teachers have a higher perception of the institution. Key-words: social support at work, organizational support, technical education.
\end{abstract}




\section{Introdução}

As questões relacionadas ao comportamento organizacional são, na atualidade, temática de interesse por parte dos gestores e pesquisadores, uma vez que estão associadas a diversos contextos, destacando-se o da saúde do trabalhador. Camelo e Angerami (2008) citam os apontamentos da Organização Internacional do Trabalho sobre os riscos biopsicossociais no trabalho, segundo os quais tais riscos consistem, por um lado, na interação entre o trabalho, seu ambiente, a satisfação no trabalho e as condições de sua organização, e, por outro lado, nas capacidades do trabalhador, suas necessidades, sua cultura e sua situação pessoal fora do trabalho, o que pode influir na saúde e no rendimento do trabalhador.

Pachane e Pereira (2005) revelam que tem-se configurado um processo de mudanças no contexto organizacional global, no qual se inserem as instituições de ensino. As autoras indicam que tais mudanças estão associadas, em especial, a alterações na organização de trabalho, aos processos de globalização da economia, ao avanço científico e tecnológico e a alterações na relação dos indivíduos com o conhecimento. Nesse contexto, insere-se a profissão docente que, por desenvolver atividade intelectual que exige inovações constantes dentro de um contexto competitivo, é impelida a um comprometimento com a organização em que se insere.

Há de considerar-se, no entanto, que quando se analisam as condições e o contexto sócio-cultural em que ocorre o trabalho docente, nem sempre este é indicador de saúde e bem-estar, tornando-se fonte de desconforto e sofrimento (Tamayo, 2007). Em muitos casos, o desequilíbrio entre o indivíduo e seu ambiente laboral contribui para 0 crescimento do sofrimento mental e dos distúrbios psicológicos de modo geral (Jacques; Amazarray, 2006). Assim, o suporte no trabalho desempenha um papel importante, podendo atuar de forma direta ou indireta para suprir as necessidades dos colaboradores, em nível emocional, instrumental e informacional (Siqueira; Gomide JR., 2008). Ainda, o suporte no trabalho, caracterizado pelo suporte social e organizacional, pode agir como um moderador das doenças ocupacionais (Seeman, 1998).

Kaplan, Cassel e Gore (1977 apud Moraes, 2007) definem suporte social a partir do quanto as pessoas estão satisfeitas com as interações com os outros, levando em consideração as suas necessidades sociais. Moraes (2007) afirma que os benefícios para a saúde física e mental do indivíduo advindos do suporte social comprovam a importância das relações saudáveis e apoio que o indivíduo recebe. Ainda, Andrade (2010) explica que este tipo de suporte é o primeiro que emerge nas relações com colegas de trabalho e também em outros contextos sociais no qual o indivíduo convive e isso contribui para a estabilidade.

Já a percepção de suporte organizacional está diretamente ligada às crenças e expectativas do indivíduo em relação ao reconhecimento e retribuição atribuído pela organização ao trabalho por ele desenvolvido. Este construto surgiu em 1986 (Eisenberger; Huntingto; Hutchinson; Sowa), baseado no pressuposto de que o trabalhador desenvolve crenças globais do quanto que a organização se preocupa. Andrade (2010) explica que o suporte organizacional objetiva satisfazer as necessidades de apoio emocional, de auto-estima, afiliação e aprovação, o que favorece os funcionários e a própria organização, facilitando o senso de obrigação dos funcionários em cuidar da organização e ajudá-la a atingir seus objetivos. 
Nesse contexto, percebe-se que o trabalho é um componente importante na vida das pessoas, despertando nos indivíduos o interesse de ganhar seus salários, ser respeitados e enriquecidos pelas competências pessoais (Berthelsen; Hjalmers; Söderfeldt, 2008). Como afirma Padovam (2005), as relações mantidas no dia a dia de trabalho não deixam de representar integrações sociais importantes na vida de um indivíduo, pois é durante o trabalho que ele pode conhecer pessoas que o auxiliem em seu crescimento e desenvolvimento profissional e pessoal. Na visão da referida autora, os indivíduos podem ainda encontrar respaldo nos colegas ou na organização, quando atravessam um momento profissional ou pessoal difícil. Dessa forma, como afirmam Berthelsen; HJalmers; Söderfeldt (2008), os empregadores têm a responsabilidade de garantir o desenvolvimento físico e social, garantindo um ambiente de trabalho saudável, valorizando o bem-estar dos colaboradores.

Deste modo, acredita-se na relevância dos estudos que apontem perspectivas de prevenção de doenças e de promoção da saúde a partir do entendimento das percepções dos trabalhadores sobre o suporte social e suporte organizacional, visto que o ambiente organizacional é permeado por fatores biopsicossociais. Tal ambiente é parte expressiva da rede de relações sociais dos indivíduos.

Neste sentido, surge um tema de pesquisa relevante. Assim, tendo como base o suporte social e organizacional no trabalho e a profissão docente, este estudo é orientado pelo seguinte problema de pesquisa: quais são as percepções de suporte no trabalho dos docentes inseridos em uma instituição de ensino técnico?

\section{Suporte social no trabalho}

O suporte social no trabalho vincula-se às variáveis relacionadas ao bem-estar no ambiente profissional. De acordo com Rodriguez e Cohen (1998), suporte social é definido como um processo pelo qual os indivíduos administram os recursos psicológicos e materiais disponíveis através das suas redes sociais, para reforçar o seu enfrentamento a eventos estressantes. O suporte social tem sido utilizado como uma ferramenta de proteção ao indivíduo contra eventos negativos decorrentes do dia a dia organizacional.

A partir de 1970 o suporte social consolidou-se por estudos desenvolvidos pelos psicólogos Cassel e Cobb, os quais enfatizaram a importância dos relacionamentos para a manutenção da saúde e redução dos níveis de estresse. Sendo assim, pode-se dizer que há uma estreita relação entre suporte social e estresse, saúde mental, doenças físicas e bem-estar. Pelo modelo de Cohen (2004), Stress buffering, acredita-se que as relações sociais apresentam benefícios à saúde dos indivíduos quando fornecem recursos psicológicos e materiais necessários para enfrentar o estresse. No entanto, o suporte social é benéfico à saúde apenas nos momentos em que o indivíduo necessita lidar com situações de estresse, não tendo um papel importante quando essas situações não se encontram presentes. Nesse aspecto, o suporte social atua diminuindo os efeitos do estresse e intervindo entre a ocorrência do evento causador do estresse e da experiência efetiva.

A necessidade faz com que os indivíduos percebam os diferentes níveis de suporte, sendo que os mais amplamente estudados referem-se ao suporte emocional, instrumental e informacional. 
As expressões de empatia, carinho e confiança vindas de amigos, familiares ou colegas de trabalho referem-se a atitudes do suporte social. Com isso, esse tipo de suporte auxilia o indivíduo a recuperar a autoestima, envolvendo a comunicação verbal e não-verbal de carinho, preocupação, auxiliando a reduzir a angústia e permitindo a expressão de sentimentos. Sendo assim, o suporte social possui como característica expressões de afeto, compreensão e estímulo à demonstração de sentimentos. A percepção de suporte social emocional no trabalho refere-se às crenças dos funcionários de que na organização existem pessoas em que se pode confiar, que se mostram preocupadas umas com as outras, que se valorizam, que se gostam. Esse suporte que o trabalhador recebe dos colegas pode fazer com que ele supere as crises com maior tranquilidade e recupere abalos em sua autoestima. Além disso, há o fortalecimento de vínculos sociais e laços afetivos que também podem proporcionar aos indivíduos sensação bem bem-estar.

O suporte social instrumental refere-se ao fornecimento de auxílio material, como assistência financeira ou ajuda nas tarefas. Pelo fornecimento de bens materiais esse tipo de suporte visa a minimizar os sentimentos de perda de controle. Assim, o suporte instrumental pode ser considerado como auxílio recebido pelo indivíduo para superar dificuldades financeiras ou materiais. Em relação à percepção de suporte instrumental percebido no trabalho, essa se relaciona à crença do indivíduo de que a empresa fornece materiais financeiros, técnicos e gerenciais que auxiliam o funcionário no desenvolvimento das suas tarefas.

O fornecimento de informações relevantes, destinadas a auxiliar o indivíduo a lidar com as dificuldades, materializando-se em forma de conselhos ou orientações para lidar com seus problemas pessoais, configura-se nas características do suporte social informacional. Esse tipo de suporte apresenta um papel fundamental, na medida em que por ele o indivíduo recebe informações sinceras, transparentes e confortáveis. O suporte social informacional se traduz sob a forma de conselhos e orientações, com o objetivo de auxiliar a resolução de problemas. Além disso, no âmbito do trabalho, esse tipo de suporte refere-se à crença, por parte do funcionário, de que a organização possui uma rede de comunicações em comum, pela qual são veiculadas informações precisas e confiáveis.

\section{Suporte organizacional no trabalho}

Suporte organizacional é tido por Eisenberger et al. (1986, p. 170), como "percepção de suporte organizacional é composto por um conjunto de crenças sobre o grau que a organização se mostra comprometida com os empregados."

Isto se refere às percepções do trabalhador acerca da qualidade do tratamento que recebe da organização em retribuição ao esforço que dedica para a realização do trabalho que lhe é definido. Essas percepções baseiam-se na frequência, intensidade e sinceridade das manifestações organizacionais de aprovação, elogio, retribuição material e social ao esforço dos seus recursos humanos. Uma percepção favorável de suporte organizacional, segundo essa perspectiva, fortaleceria a expectativa esforço-resultado e o envolvimento afetivo do empregado com a organização, resultando em maior esforço do empregado para atingir os objetivos organizacionais. 
Esta teoria de troca social propõe que se desenvolva entre os empregados e organizações uma recíproca troca, ou seja, o trabalhador deve cumprir com as suas obrigações e manter um bom desempenho e empresa deve cumprir, por sua vez, com as obrigações legais, financeiras e morais que são exigidas para com os seus colaboradores.

A percepção de suporte organizacional ocorre a partir de um processo de personificação da organização, o que significa que os empregados veem as ações dos agentes organizacionais como ações da própria organização. Normalmente, os membros das organizações atribuem a elas características humanas. As crenças sobre as retribuições organizacionais dependem do mesmo processo de atribuição utilizado para inferir o comprometimento de outras pessoas nas relações sociais (Tamayo; Trócolli, 2002). Desta forma, o trabalhador passa a desenvolver percepções favoráveis do suporte organizacional quando julga que as retribuições organizacionais são sinceras, bem intencionadas e que não sofram qualquer tipo de manipulação.

Continuando nesta linha de pensamento nos deparamos com as inúmeras vantagens que as organizações que fazem uso do suporte organizacional passam a ter frente as demais organizações que não fazem uso desta ferramenta de gestão. O suporte organizacional é percebido como importante para determinação do comportamento dos seus funcionários. Frente a isto se percebe que as organizações que mantiverem suas políticas alinhadas com as propostas de percepção de suporte organizacional, tratamento justo, suporte da supervisão, recompensas organizacionais, condições favoráveis de trabalho e preocupação por parte da empresa com o bem-estar dos trabalhadores obterão melhores resultados. Neste processo, ao dispensar tratamentos satisfatórios aos seus funcionários, as organizações despertam nesses um sentimento de obrigação, fazendo com que se comportem de maneira a beneficiar a organização, aumentando o seu comprometimento e desempenho no trabalho.

Também é importante relatar acerca do princípio de reciprocidade. Neste contexto,

as relações sociais são regidas por um principio moral, universalmente aceito, de caráter maleável e não padronizados, que define como obrigação 0 ato de retribuir um beneficio recebido. Existem duas exigências básicas e interdependentes decorrentes deste princípio: (1) deve-se ajudar a quem nos ajuda e (2) não se deve prejudicar a quem nos beneficia. (Siqueira 1996, p. 179)

Desta forma temos que o princípio da reciprocidade pode ser visto como uma dimensão presente nos sistemas de valores e, especificamente, como um dos principais componentes presentes nos códigos morais e evidencia-se que o princípio de reciprocidade não é derivado de papéis ou posições ocupadas pelas partes envolvidas em uma relação social, mas sim consequência dos atos de cada uma, nesta interação. Assim, este princípio é aplicável nas mais diversas situações de interação social, sempre que uma parte (doador) oferece ajuda, auxílio, presta um favor, ou beneficia outra pessoa (receptor):

quando um indivíduo é admitido por uma organização, ele é alocado num dado cargo para o qual estão prescritas determinadas ações. Para retribuir, recompensar ou pagar estes comportamentos de trabalho, o sistema oferece ao seu empregado uma certa quantia em dinheiro (salário) 
e adiciona a ela o direito de empregado ter acesso aos benefícios e vantagens integrantes dos planos de incentivos oferecidos pelo sistema. (Siqueira, 1996, p. 181)

Tendo em vista a norma da reciprocidade, esta se torna adequada para o entendimento da percepção de suporte organizacional a partir do momento em que se visualiza o empregado como receptor e a organização como doadora. Os funcionários formam percepções acerca das intenções e atos organizacionais, principalmente pelas políticas e práticas de gestão de pessoas. Assim, as doações organizacionais são entendidas como os atos da gerência que definem a política de gestão de pessoas no dia a dia organizacional, enquanto que, por outro lado, a formação da percepção de suporte organizacional acontece devido à crença do funcionário enquanto receptor de doações atuais ou potenciais (Siqueira; Gomide Junior, 2004). Esta relação é evidenciada na figura 1.

Figura 1 - Reciprocidade e suporte organizacional.

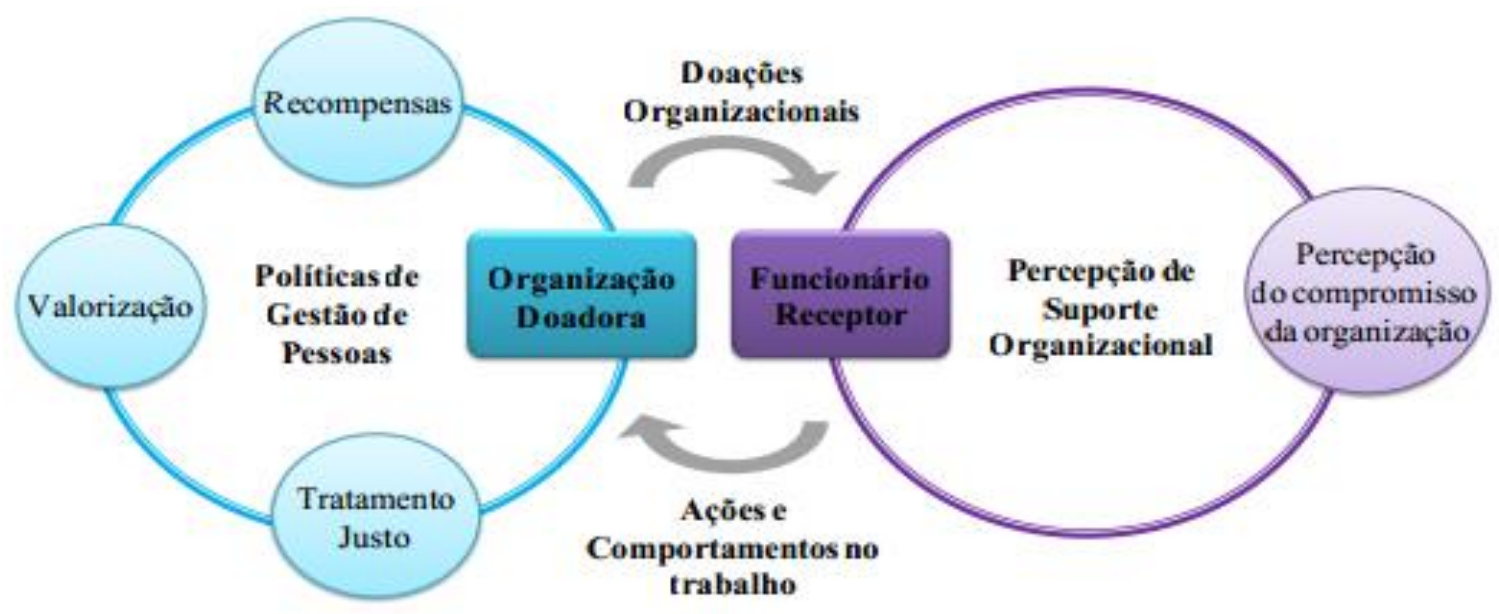

Fonte: Adaptado de Siqueira; Gomide Junior (2004).

É importante salientar que a percepção de suporte organizacional incorpora à identidade do funcionário sua situação enquanto membro da organização e seu papel na mesma. Isto faz com que os funcionários expressem comportamentos tais como: a) maior tendência em interpretar os ganhos e perdas da organização como seus; b) criação de vieses no julgamento das ações da organização; c) maior internalização dos valores e normas da organização.

\section{Escola como organização}

A escola sempre foi organizada como uma unidade social, ou agrupamento humano, intencionalmente construída e reconstruída, a fim de atingir objetivos específicos. As escolas são, pois, organizações, e nelas sobressai a interação entre as pessoas para a promoção da formação humana: "a instituição escolar caracteriza-se por ser um sistema de relações humanas e sociais com fortes características interativas, que a diferenciam das empresas convencionais" (Libâneo; Oliveira; Toschi, 2003, p. 316). 
Ainda para esses autores, a escola tem como objetivo primordial o desenvolvimento das potencialidades físicas, cognitivas e afetiva dos alunos, por meio da aprendizagem dos conteúdos (conhecimentos, habilidades, procedimentos, atitudes, valores), para se tornarem cidadãos participativos na sociedade em que vivem. $O$ ensino e a aprendizagem do aluno é o objetivo principal, sendo que esta tarefa recai na atividade docente. A organização escolar necessária é aquela que favorece o trabalho dos docentes, existindo interdependência entre os objetivos, as funções da escola e a organização e gestão do trabalho escolar.

Desta forma evidencia-se a escola, sua importância e a função que exerce na sociedade, permeando um papel de agente formador de novos valores que renovarão a cultura e o desenvolvimento de novas teorias para o conhecimento humano. A escola é a base da renovação dos costumes, código de ética e do ensino dos valores que norteiam a convivência que permite a manutenção da coesão de mentes distintas em regras comuns na formação do cidadão.

O clima organizacional pode unir ou dividir os sentimentos, um estímulo ou um obstáculo à motivação e à iniciativa dos vários membros da escola. Representa um fator vital para o alcance ou não dos objetivos dos membros da comunidade escolar. O clima institucional também influi na maior ou menor gravidade que os conflitos entre os diversos segmentos da escola podem adquirir e, dessa forma, ajuda ou atrapalha a consecução dos seus objetivos.

É importante observar também que as pessoas estão ligadas, ao mesmo tempo, à cultura organizacional da escola e às diversas subculturas a que pertencem. Esta dupla maneira de pertencer influencia a forma como cada pessoa percebe a cultura organizacional maior e, consequentemente, como ela percebe o clima da escola. As complexidades das culturas e do clima organizacional são úteis para lembrar que estamos buscando qualidade em uma organização de pessoas humanas, permeáveis a ideias e ideais, que trazem memórias de sucessos e fracassos, mas que são também capazes de compartilhar visões de um futuro melhor e mais relacionado às suas próprias ações.

\section{Metodologia}

O presente estudo é de natureza descritiva, de caráter quantitativo e busca identificar as possíveis relações dentre um conjunto de variáveis apresentadas no modelo teórico. A pesquisa descritiva tem como principal objetivo informar o pesquisador sobre situações, fatos, opiniões ou comportamentos da população analisada, buscando mapear a distribuição de um fenômeno (Triviños, 2007). Ainda, tais estudos descrevem características de determinada população ou fenômeno ou, então, o estabelecimento de relações entre variáveis (Gil, 2002).

O caráter quantitativo da pesquisa busca quantificar os dados e generalizar os resultados da amostra para a população alvo. Para tal, usualmente, faz-se uso de questionário. (Vergara, 2006). Além disso, como forma de identificar as possíveis relações das variáveis apresentadas, será utilizada abordagem metodológica de investigação de estudo de caso. Yin (2005) define o estudo de caso com base nas características do fenômeno em estudo, no caso desse estudo uma escola de ensino técnico, e com base num conjunto de características associadas ao processo de coleta de dados e as estratégias de análise dos mesmos. 
A amostra da pesquisa é composta por 17 docentes de um colégio técnico de Santa Maria. Para a realização do estudo utilizou-se a escala de percepção de suporte social no trabalho (EPSST), construída por Gomide Jr., Guimarães e Damásio (2004). Esta escala é composta por 18 itens, agrupados em três dimensões: percepção de suporte social emocional, suporte social instrumental e suporte social informacional no trabalho. Já para a análise do suporte organizacional empregou-se a escala de percepção de suporte organizacional (EPSO), medida originalmente desenvolvida por Eisenberger et al. (1986) e adaptada e validada no contexto brasileiro por Siqueira (1995). A ESPO, composta em sua versão reduzida por oio questões, caracteriza-se por uma escala unidimensional. Além das escalas, o questionário foi composto de dados demográficos e funcionais.

\section{Resultados}

Esta seção está dividida em três partes. A primeira aborda, sumariamente, a caracterização dos docentes participantes do estudo. Em seguida, o foco constitui a análise da percepção dos docentes a respeito do suporte social no trabalho. Por fim, apresentam-se os resultados referentes à percepção dos docentes acerca do suporte organizacional.

Faz-se necessário conhecer a amostra pesquisada. Para isto, foram realizados os testes estatísticos descritivos e de frequência para as variáveis sócio-demográficas e profissionais. Compuseram a amostra 17 docentes, identificados, na tabela 1, por meio de dados referentes à seus dados demográficos (idade, gênero, estado civil e formação) e a sua vida profissional (tempo de atuação como docente, tempo que trabalha na instituição, carga horária semanal, carga horária diária, média de alunos por turma e horas em atividades extraclasses).

Tabela 1 - Perfil dos professores pesquisados do colégio técnico de Santa Maria.

\begin{tabular}{|l|l|c|c|c|c|c|}
\hline \multicolumn{1}{|c|}{ Variáveis } & Entrevistados & $\begin{array}{c}\text { Frequênci } \\
\mathrm{a}\end{array}$ & $\bar{X}$ & DP & Mediana & Mín./Máx. \\
\hline Idade & \multicolumn{1}{|c|}{-} & - & 41,82 & $\pm 10,36$ & 45 & $28-60$ \\
\hline Sexo & Feminino & $41,17 \%$ & - & - & - & - \\
\hline & Masculino & $58,83 \%$ & - & - & - & - \\
\hline Estado Civil & Solteiro & $17,6 \%$ & - & - & - & - \\
\hline & Casado & $41,3 \%$ & - & - & - & - \\
\hline & Divorciado & $11,7 \%$ & - & - & - & - \\
\hline & União estável & $29,4 \%$ & - & - & - & - \\
\hline Formação & Graduação & $23 \%$ & & & & \\
\hline & Mestrado & $34,9 \%$ & & & & \\
\hline & Doutorado & $25 \%$ & & & & \\
\hline & Não responderam & $17,1 \%$ & & & & $1-35$ \\
\hline $\begin{array}{l}\text { Tempo de atuação como } \\
\text { docente (anos) }\end{array}$ & - & - & 12,12 & $\pm 9,42$ & 11 & $1-45$ \\
\hline $\begin{array}{l}\text { Tempo que trabalha na } \\
\text { Instituição (anos) }\end{array}$ & - & - & 10,65 & $\pm 12,64$ & 3 & $11-40$ \\
\hline $\begin{array}{l}\text { Carga horária semanal } \\
\text { (horas) }\end{array}$ & - & - & 31,24 & $\pm 12,37$ & 40 & $3-8$ \\
\hline $\begin{array}{l}\text { Carga Horária diária } \\
\text { (horas) }\end{array}$ & - & - & 6,75 & $\pm 1,83$ & 8 & \\
\hline
\end{tabular}




\begin{tabular}{|l|c|c|c|c|c|c|}
\hline $\begin{array}{l}\text { Média de alunos por } \\
\text { turma }\end{array}$ & - & - & 24,29 & $\pm 3,56$ & 25 & $18-30$ \\
\hline $\begin{array}{l}\text { Atividades extraclasses } \\
\text { (horas) }\end{array}$ & - & - & 11, & $\pm 9,26$ & 9 & $2-30$ \\
\hline
\end{tabular}

Fonte: Dados da pesquisa.

Ao analisar os dados apresentados quanto ao perfil dos docentes que responderam ao questionário, percebe-se que estes professores têm faixa etária média de 41,82 anos, com uma variação entre o mais jovem e o mais velho de 28-60 anos. Verifica-se, também, que a maioria dos profissionais que responderam o questionário são homens, casados, correspondendo a 58,83\%. O número de mulheres que contribuíram respondendo o questionário foi de $41,17 \%$, nota-se então uma variação de $17,66 \%$ no comparativo entre os gêneros.

Evidenciam-se, ainda, os índices referentes à formação deste grupo de professores, uma vez que, a LDB exige certificação em âmbito de graduação para atuar no ensino médio. Entretanto, deste grupo de professores tão somente $23 \%$ apresentam apenas a graduação, uma vez que $34,9 \%$ têm mestrado e $25 \%$ destes tem doutorado. Tal formação pode significar muitas coisas: ao desejo de formação e aprimoramento desses profissionais; o reflexo dos planos de carreiras da Educação Básica Técnica e Tecnológica, em âmbito federal, uma vez que tais planos incitam a buscar qualificação, uma vez que o aumento salarial torna-se significativos com as mudanças de níveis de formação.

Os colaboradores desta investigação atuam na carreira docente em média há 12,12 anos e trabalham na instituição pesquisada a mais de 10 anos. Nota-se, que neste âmbito profissional, estes sujeitos sinalizam em suas respostas que trabalham em média 31,24 horas semanais, uma vez alguns professores atuam em média 2 horas diárias e outros 8 horas frente aos alunos.

No que tangem as turmas de alunos do colégio técnico investigado existe uma média de 24,29 alunos. Dessa forma, as turmas dos professores participantes da investigação são compostas de 18 a 30 alunos e estes professores recebem em média de 2 a 30 horas semanais para desenvolver atividades extra classe. Assim, nas próximas subseções serão realizadas as análises da percepção dos docentes sobre o suporte social e o suporte organizacional no trabalho.

\section{Suporte social no trabalho: a percepção dos docentes do ensino técnico}

A fim de compreender a percepção dos docentes do ensino técnico acerca do suporte social no trabalho realizou-se a técnica estatística da análise da frequência. Ressalta-se que a escolha deste teste deu-se devido à adequação do mesmo a necessidade do estudo e ao número reduzido de participantes.

Por meio da análise do quadro 1 percebe-se que no fator 1 predominam as variáveis associadas à dimensão suporte social informacional do modelo EPSST, relacionada ao fornecimento de informações como apoio ao indivíduo no desenvolvimento de seu trabalho (Seeman, 1998). Esse tipo de suporte inclui receber de outras pessoas, inclusive de superiores, noções indispensáveis para que o indivíduo por guiar suas ações ao dar solução a um problema ou tomar uma decisão (Siqueira, 2008).

Já no fator 2 evidencia-se a predominância da dimensão suporte social emocional do modelo EPSST, sendo, portanto, a denominação do fator. Esse fator contempla Regae: Rev. Gest. Aval. Educ. $\quad$ Santa Maria v. 3 n. 5 Jan./jun. 2014 p. 33-49 
variáveis associadas à expressão de empatia, carinho e preocupação para com outro, proporcionando oportunidades de expressão de sentimentos e emoções (Cohen, 2004).

O último fator, fator 3 , retrata a percepção de apoio material, denominado suporte social instrumental no trabalho. A percepção de suporte instrumental refere-se ao entendimento, por parte dos docentes pesquisados, de que há na escola insumos materiais, financeiros, técnicos e gerenciais necessários à realização de suas atividades (Gomide Junior, Guimarães e Damásio, 2004).

Considerando as variações da escala de (1) discordo totalmente a (5) concordo totalmente, os resultados do quadro 1 evidenciam que as variáveis de maior concordância ( $<50 \%$ - na soma de "concordo" e "concordo totalmente"), nestes fatores, entre os respondentes foram: há facilidade de acesso às informações importantes; os docentes têm os equipamentos necessários para as suas tarefas; as pessoas gostam umas das outras; as pessoas podem compartilhar seus problemas pessoais; pode-se confiar nos superiores; há ajuda financeira para que os docentes se especializem; e os equipamentos estão sempre em boas condições de uso.

Porém, ressalta-se que os maiores valores concentram-se em variáveis pertencentes ao fator 1 e fator 3, sendo, respectivamente: os docentes têm equipamentos necessários para as suas tarefas; e os equipamentos estão sempre em boas condições de uso. Isto demonstra que os docentes percebem a existência do suporte social informacional e do suporte social instrumental, principalmente orientados pela suficiência e boa conservação dos equipamentos necessários a suas tarefas (Siqueira eGomide JR., 2008).

Em contrapartida, às variáveis que evidenciam a menor concordância $(<50 \%$ - na soma de "indiferente", "discordo" e "discordo totalmente") nestes fatores são: as informações circulam claramente entre os setores da escola; as pessoas são amigas umas das outras; pode-se confiar nas pessoas; as pessoas gostam umas das outras; as pessoas se preocupam umas com as outras; e são pagos salários compatíveis com os esforços dos docentes.

Destaca-se que a menor concordância aparecem nas variáveis "as pessoas são amigas umas das outras" e "as pessoas se preocupam umas com as outras", componentes do fator 2. Estes resultados revelam a menor existência do suporte social emocional, relacionado à percepção da doação de recursos afetivos pela rede social, incluindo compreensão, atenção e preocupação com o outro (Siqueira, 2008), refletindo a boa interação entre os colaboradores (Oliveira, Tristão E Neiva, 2006).

Quadro 1 - Resultados suporte social no trabalho (fator 1, fator 2 e fator 3).

\begin{tabular}{|l|c|c|c|c|c|}
\hline \multicolumn{7}{|c|}{ Fator 1- Suporte social informacional no trabalho } \\
\hline \multicolumn{1}{|c|}{ Variáveis } & $\begin{array}{c}\text { Discordo } \\
\text { Totalmente } \\
\%\end{array}$ & $\begin{array}{c}\text { Discordo } \\
\%\end{array}$ & $\begin{array}{c}\text { Indiferente } \\
\%\end{array}$ & $\begin{array}{c}\text { Concordo } \\
\%\end{array}$ & $\begin{array}{c}\text { Concordo } \\
\text { Totalmente \% }\end{array}$ \\
\hline $\begin{array}{l}\text { As informações importantes } \\
\text { para o trabalho são } \\
\text { compartilhadas por todos. }\end{array}$ & 6,25 & 25 & 18,75 & 31,25 & 18,75 \\
\hline $\begin{array}{l}\text { As informações importantes } \\
\text { são repassadas com } \\
\text { agilidade. }\end{array}$ & 6,25 & 31,25 & 12,5 & 31,25 & 18,75 \\
\hline
\end{tabular}




\begin{tabular}{|c|c|c|c|c|c|}
\hline $\begin{array}{l}\text { Os superiores compartilham } \\
\text { informações importantes. }\end{array}$ & 6,25 & 31,25 & 12,5 & 31,25 & 18,75 \\
\hline $\begin{array}{l}\text { Há facilidade de acesso às } \\
\text { informações importantes. }\end{array}$ & 6,25 & 18,75 & 12,5 & 50 & 12,5 \\
\hline $\begin{array}{l}\text { Os docentes são } \\
\text { informados sobre as } \\
\text { decisões que envolvem o } \\
\text { trabalho. }\end{array}$ & 6,25 & 25 & 12,5 & 37,5 & 18,75 \\
\hline $\begin{array}{l}\text { Os docentes têm os } \\
\text { equipamentos necessários } \\
\text { para as suas tarefas. }\end{array}$ & 0 & 6,25 & 12,5 & 43,75 & 37,5 \\
\hline $\begin{array}{l}\text { As informações circulam } \\
\text { claramente entre setores da } \\
\text { escola. }\end{array}$ & 6,7 & 26,7 & 26,7 & 33,2 & 6,7 \\
\hline \multicolumn{6}{|c|}{ Fator 2 - Suporte social emocional no trabalho } \\
\hline $\begin{array}{l}\text { As pessoas são amigas } \\
\text { umas das outras. }\end{array}$ & 6,7 & 26,7 & 33,3 & 33,3 & 0 \\
\hline $\begin{array}{l}\text { Pode-se confiar nas } \\
\text { pessoas. }\end{array}$ & 6,25 & 31,25 & 18,75 & 31,25 & 12,5 \\
\hline $\begin{array}{l}\text { As pessoas gostam umas } \\
\text { das outras. }\end{array}$ & 6,25 & 18,75 & 18,75 & 56,25 & 0 \\
\hline $\begin{array}{l}\text { As pessoas podem } \\
\text { compartilhar seus } \\
\text { problemas pessoais. }\end{array}$ & 6,7 & 26,7 & 13,13 & 53,3 & 0 \\
\hline $\begin{array}{l}\text { As pessoas se preocupam } \\
\text { umas com as outras. }\end{array}$ & 6,25 & 25 & 31,25 & 31,25 & 6,25 \\
\hline $\begin{array}{l}\text { Pode-se confiar nos } \\
\text { superiores. }\end{array}$ & 6,25 & 18,75 & 18,75 & 50 & 6,25 \\
\hline \multicolumn{6}{|c|}{ Fator 3 - Suporte social instrumental no trabalho } \\
\hline $\begin{array}{l}\text { São pagos salários } \\
\text { compatíveis com os } \\
\text { esforços dos docentes. }\end{array}$ & 0 & 25 & 31,25 & 18,75 & 25 \\
\hline $\begin{array}{l}\text { Há ajuda financeira para } \\
\text { que os docentes se } \\
\text { especializem. }\end{array}$ & 0 & 6,6 & 26,7 & 26,7 & 40 \\
\hline $\begin{array}{l}\text { Os equipamentos estão } \\
\text { sempre em boas condições } \\
\text { de uso. }\end{array}$ & 6,25 & 12,5 & 12,5 & 56,25 & 12,5 \\
\hline
\end{tabular}

Fonte: Dados da pesquisa.

\section{Suporte organizacional: uma relação de troca e reciprocidade entre docente e escola}

Do mesmo modo que no suporte social, utilizou-se a técnica estatística de frequência para a realização da análise do suporte organizacional entre os docentes e a escola. Considerando as variáveis que formam o suporte organizacional, percebe-se que esse está relacionado à percepção dos docentes à cerca da retribuição e do reconhecimento dado pela organização ao seu trabalho, além do apoio sócio-técnico que são necessários para sua realização (Tamayo e Trócolli, 2002).

Dessa forma, nota-se no quadro 2 , que as variáveis de maior concordância $(<50 \%$ na soma de "concordo" e "concordo totalmente"), com relação ao suporte organizacional no trabalho, de acordo com os respondentes foram: existe o cumprimento das obrigações 
financeiras com os empregados; é possível obter ajuda desta empresa quando tenho um problema;esta empresa realmente preocupa-se com meu bem estar; esta empresa estaria disposta a ampliar suas instalações para me ajudar a utilizar minhas melhores habilidades no desempenho do meu trabalho e a empresa está pronta a me ajudar quando eu preciso de um favor especial.

Evidencia-se que os docentes possuem uma excelente percepção do suporte organizacional oferecido pela instituição devido ao fato de cinco dentre as oito questões do constructo apresentarem variáveis de maior concordância. Dentre elas destacam-se, com maior concordância, as variáveis "existe o cumprimento das obrigações financeiras com os empregados" e "é possível obter ajuda desta empresa quando tenho um problema". De acordo com Rhoades e Eisenberger (2002), os cuidados, a aprovação e o respeito conotados pela percepção de suporte organizacional devem atender às necessidades socioemocionais dos trabalhadores, levando-os a incorporar seu papel como membro da organização, podendo ter resultado positivo tanto para os empregados como, por exemplo, o aumento da satisfação profissional, quanto para a organização, como, por exemplo, o aumento do comprometimento dos colaboradores (Rhoades; Eisenberger, 2002).

Com relação a menor concordância, obteve-se apenas dois itens: "há recompensa financeira pelos esforços dos empregados" e "esta empresa preocupa-se com a minha satisfação no trabalho". Pelo fato dos professores serem concursados, a instituição não possui autonomia para recompensá-los financeiramente, porém, nota-se uma carência no que tange a preocupação da escola com a satisfação dos docentes. Isso contraria aspectos do suporte organizacional, o qual envolve a preocupação da organização em relação ao bem-estar e satisfação dos colaboradores, bem como o apoio sócio-técnico (Eisenberger et al., 1986; Tamayo e Trócolli, 2002).

Quadro 2 - Resultados suporte organizacional no trabalho.

\begin{tabular}{|l|c|c|c|c|c|}
\hline \multicolumn{1}{|c|}{ Suporte organizacional no trabalho } \\
\hline \multicolumn{1}{|c|}{ Variáveis } & $\begin{array}{c}\text { Discordo } \\
\text { Totalmente } \\
\%\end{array}$ & $\begin{array}{c}\text { Discordo } \\
\%\end{array}$ & $\begin{array}{c}\text { Indiferente } \\
\%\end{array}$ & $\begin{array}{c}\text { Concordo } \\
\%\end{array}$ & $\begin{array}{c}\text { Concordo } \\
\text { Totalmente } \%\end{array}$ \\
\hline $\begin{array}{l}\text { Há recompensa financeira } \\
\text { pelos esforços dos } \\
\text { empregados. }\end{array}$ & 37,5 & 12,5 & 25 & 18,75 & 6,25 \\
\hline $\begin{array}{l}\text { Existe o cumprimento das } \\
\text { obrigações financeiras com } \\
\text { os empregados. }\end{array}$ & 6,25 & 0 & 25 & 12,5 & 56,25 \\
\hline $\begin{array}{l}\text { É possível obter ajuda } \\
\text { desta empresa quando } \\
\text { tenho um problema. }\end{array}$ & 0 & 0 & 37,5 & 50 & 12,5 \\
\hline $\begin{array}{l}\text { Esta empresa realmente } \\
\text { preocupa-se com meu bem } \\
\text { estar. }\end{array}$ & 0 & 6,25 & 37,5 & 37,5 & 18,75 \\
\hline
\end{tabular}




\begin{tabular}{|l|c|c|c|c|c|}
\hline $\begin{array}{l}\text { Esta empresa estaria } \\
\text { disposta a ampliar suas } \\
\text { instalações para me ajudar } \\
\text { a utilizar minhas melhores } \\
\text { habilidades no desempenho } \\
\text { do meu trabalho. }\end{array}$ & 6,25 & 0 & 37,5 & 31,25 & 25 \\
\hline $\begin{array}{l}\text { Esta empresa está pronta a } \\
\text { me ajudar quando eu } \\
\text { preciso de um favor } \\
\text { especial. }\end{array}$ & 6,25 & 0 & 37,5 & 56,25 & 0 \\
\hline $\begin{array}{l}\text { Esta empresa preocupa-se } \\
\text { com minha satisfação no } \\
\text { trabalho. }\end{array}$ & 6,25 & 6,25 & 50 & 25 & 12,5 \\
\hline $\begin{array}{l}\text { Esta empresa tenta fazer } \\
\text { com que meu trabalho seja } \\
\text { o mais interessante } \\
\text { possível. }\end{array}$ & 6,25 & 6,25 & 37,5 & 37,5 & 12,5 \\
\hline
\end{tabular}

Fonte: Dados da pesquisa.

Os resultados da pesquisa demonstraram uma melhor percepção dos docentes do suporte social informacional e do suporte social instrumental, com relação ao suporte social emocional, bem como uma alta percepção do suporte organizacional oferecido pela instituição. Portanto, no contexto das instituições de ensino, nota-se a relevância de compreender a influência de suporte social e organizacional no trabalho, que atua como fonte importante de apoio e até mesmo de motivação para os docentes.

\section{Considerações finais}

O ambiente de trabalho docente é caracterizado por muitos autores como sendo de constantes pressões, estresse, desgaste emocional e físico, contribuindo para a concepção de que a docência é uma das atividades mais estressantes (Reis et al.; 2005). Desse modo, atualmente, percebe-se a intensificação do trabalho docente, tendo em vista o acúmulo de atividades, o que, consequentemente, ocasiona maiores desgastes e insatisfação por parte dos indivíduos. (Reis et al. 2005; Oliveira, 2006).

Em relação ao suporte social no trabalho, observou-se que há uma maior percepção do suporte social informacional e do suporte social instrumental, caracterizado, principalmente, por os docentes terem acesso aos equipamentos necessários para a realização de suas atividades e esses estarem em boas condições de uso. Os resultados da pesquisa também revelaram uma baixa percepção do suporte social emocional. Nesse sentido, observou-se, na percepção dos docentes da escola, que a baixa valorização do suporte emocional ocorre devido às pessoas não se demostrarem tão amigáveis e nem tão preocupadas umas com as outras.

Considerando o suporte organizacional, pode-se observar que os docentes apresentam uma percepção elevada, principalmente no que tange os aspectos das obrigações financeiras da instituição, que são cumpridas, e também da disposição da instituição para oferecer apoio em eventuais problemas. No entanto, os docentes apresentaram baixa percepção com relação há falta de recompensa financeira oferecidas pela instituição, o que explica-se pelo fato dos professores sem concursados, mas também no que tange a falta de preocupação da instituição com a satisfação no trabalho docente. 
Desse modo, pode-se evidenciar que este estudo respondeu ao seu questionamento central, no qual foi possível analisar as percepções dos docentes com relação ao suporte no trabalho. Diante destas considerações, pode-se perceber que este estudo avançou na linha de entendimento acerca dos aspectos envolvidos nas relações de trabalho dos docentes, tendo em vista a realidade vivenciada por eles em uma instituição de ensino técnico.

Como fatores limitantes, pode-se citar o baixo número de docentes participaram da pesquisa, limitando as análises estatísticas realizadas. Sugere-se que estudos futuros avancem nesta linha, uma vez que é reconhecida a importância do papel do professor para a sociedade atual. Neste sentido, estudos que busquem investigar a relação entre suporte no trabalho (organizacional e social) em professores de outras realidades, com vistas à comparação de resultados.

\section{Referências}

ANDRADE, Tais de. Valores organizacionais, suporte social e organizacional no trabalho: um estudo no setor bancário. Santa Maria: UFSM, 2010. 143f. Dissertação (mestrado em Administração). Universidade Federal de Santa Maria.

BERTHELSEN, Hanne; HJALMERS, Karin; SÖDERFELDT, Bjorn. Perceived social support in relationto work among Danish general dental practitioners in private practices. Eur J Oral Sci, v. 16, 2008, p. 157-163.

CAMELO, Henrique; SILVIA Helena; ANGERAMI, Emília Luigia Saporiti. Riscos psicossociais no trabalho que podem levar ao estresse: uma análise da literatura. Ciência, Cuidado e Saúde, v. 7, 2008, 232-240.

COHEN, Sheldon. Social relationships and health. American Phychogist, v. 59, 2004, p. 679-684.

EISENBERGER, Robert. et al. Perceived organizational support. Journal of Applied Psychology, v.71, n. 3, p. 500-507, 1986.

GIL, Antonio Carlos. Métodos e técnicas de pesquisa social. São Paulo: Atlas, 2002.

GOMIDE Sinesio Junior; GUIMARÃES, Luciele Caixeta; DAMÁSIO, Lucileide. Construção e validação de um instrumento de medida de percepção de suporte social no trabalho. SEMINÁRIO DE PESQUISA DO GRUPO INTERINSTITUCIONAL DE PESQUISA EM BEM-ESTAR E SUPORTE SOCIAL E TRABALHO, 2, Uberlândia. Anais ... Uberlândia: UFU, 2004.

JACQUES, Maria da Graça Corrêa; AMAZARRAY, Mayte Raya. Trabalho bancário e saúde mental no paradigmada excelência. Boletim da Saúde, v. 20, n. 1, 2006, p. 93-106.

LIBÂNEO, José Carlos; OLIVEIRA João Ferreira; TOSCHI, Mirza Seabra. Educação escolar: políticas, estrutura e organização. São Paulo: Cortez, 2003.

MORAES, Elton Ramos. Percepções de suporte organizacional e social no trabalho como antecedentes da percepção de saúde da organização. Uberlândia: UFU, 2007. $125 f$. Dissertação (mestrado em Psicologia). Universidade Federal de Uberlândia.

OLIVEIRA, Petter Ricardo de; TRISTÃO, Rosana Maria; NEIVA, Elaine Rabelo. Burnout e suporte organizacional em profissionais de UTI-Neonatal. Educação profissional: ciência e tecnologia, v. 1, n. 1, 2006. 
PACHANE, Graziela Giusti; PEREIRA. Elisabete Monteiro de Aguiar. A importância da formação didático-pedagógica e a construção de um novo perfil para docentes universitários. Revista Iberoamericana de Educação, 2005.

PADOVAN, Valquiria Aparecida Rossi. Antecedentes de bem-estar no trabalho: percepções de suportes e de justiça. São Paulo: Unimep, 2005. 122f. Dissertação (mestrado em Psicologia da Saúde). Universidade Metodista de São Paulo.

REIS, Eduardo José Farias Borges dos et al. Trabalho e distúrbios psíquicos em professores da rede municipal de Vitória da Conquista, Bahia, Brasil. Cad. Saúde Pública, v. 21 , n. 5,2005, p. 1480-1490.

RHOADES, Linda; EISENBERGER Robert. Perceived organizational support: a review of the literature. Journal of Applied Psychology, v. 87, n. 4, 2002, p. 698-714.

RODRIGUEZ, Mario; COHEN, Sheldon. Social support. Encyclopedia of mental health. v. 3, 1998, p. 535-544.

SEEMAN, Teresa. Social support and social conflict. 1998. Disponível em: <http://www. macses.ucsf.edu/research/psychosocial/socsupp.php >. Acesso em: 28 maio, 2012.

SIQUEIRA, Mirlene Maria Matias. Cognições relativas ao trabalho. In: TAMAYO, A.; BORGES ANDRADE, J., et al (Ed.). Trabalho, organizações e cultura: São Paulo: Anpep, 1996, p. 173-184.

SIQUEIRA, Mirlene Maria Matias; GOMIDE Júnior Sinésio. Suporte no trabalho. In: SIQUEIRA, Mirlene Maria Matias (org.). Medidas do comportamento organizacional: ferramentas de diagnóstico e de gestão. Porto Alegre: Artmed, 2008.

SIQUEIRA, Mirlene Maria Matias; GOMIDE Júnior Sinésio. Vínculos do indivíduo com o trabalho e com a organização. In: ZANELLI, J. C.; BORGES-ANDRADE, J. E., et al (ed.). Psicologia, organizações e trabalho no Brasil. Porto Alegre: Artmed, 2004, p. 300-328. SIQUEIRA, Mirlene Maria Matias. Antecedentes de comportamentos de cidadania organizacional: a análise de um modelo pós-cognitivo. Brasília: UNB, 1995. 239f. Tese (doutorado em Psicologia). Universidade de Brasília.

TAMAYO, Mauricio Robayo; TRÓCCOLI, Bartholomeu Tôrres. Exaustão emocional: relações com a percepção de suporte organizacional e com as estratégias de coping no trabalho. Estudos de Psicologia, v. 7, n. 1, 2002, p. 37-46.

TAMAYO, Álvaro. Impactos dos valores da organização sobre o estresse ocupacional. RAC Eletrônico, v. 1, n. 2, 2007, p. 20-33.

TRIVIÑOS, Augusto Nibaldo Silva. Introdução à pesquisa em ciências sociais: a pesquisa qualitativa em educação. São Paulo: Atlas, 2007.

VERGARA, Sylvia Constant. Projetos e relatórios de pesquisa em administração. São Paulo: Atlas, 2006.

YIN, Robert. Estudo de caso: planejamento e métodos. Porto Alegre: Bookman, 2005.

Marinês Verônica Ferreira é bacharel em Química Industrial pela UFSM. Atualmente, é estudante nos cursos de Química licenciatura, Gestão Educacional e Educação nas Ciências na UFSM.

Endereço: Rua Gonçalves Ledo, 895 - 97110-320 - Santa Maria - RS - Brasil.

E-mail: marinesmvf@hotmail.com. 
Stefania Tonin é bacharel em Administração pela Universidade Federal de Santa Maria e estudante do Programa de Pós-Graduação em Administração na mesma universidade.

Endereço: Avenida Roraima, 1000 - 97105-900 - Santa Maria - RS - Brasil.

E-mail: stefaniatonin@gmail.com.

Taís Corrêa Almeida é bacharel em Farmácia pelo Centro Universitário Franciscano. Atualmente, é estudante do curso de doutorado em Ciências Farmacêuticas da Universidade Federal de Santa Maria.

Endereço: Avenida Roraima, 1000 - 97105-900 - Santa Maria - RS - Brasil.

E-mail: tais.correa@yahoo.com.br.

Vívian Flores Costa é estudante do curso de mestrado em Administração da Universidade Federal de Santa.

Endereço: Avenida Roraima, 1000 - 97105-900 - Santa Maria - RS - Brasil.

E-mail: vivianfc 06@hotmail.com.

Leila Maria Araújo Santos é professora adjunta na Universidade Federal de Santa Maria.

Endereço: Avenida Roraima, 1000 - 97105-900 - Santa Maria - RS - Brasil. E-mail: leilamas@gmail.com.

Recebido em 4 de outubro de 2013.

Aceito em 14 de janeiro de 2014. 